\section{Anoxic hepatic and intestinal injury from carbon monoxide poisoning}

Severe carbon monoxide poisoning results in widespread anoxic damage to many organs as a result of competition with oxygen for binding sites on the haemoglobin molecule and the consequent displacement of oxygen. ${ }^{12}$ The anoxia principally affects the central nervous system and myocardium, although there has been one report of abdominal pain and bloody diarrhoea possibly as a result of anoxic damage to the intestinal wall. ${ }^{3}$ We have been unable to find a description of anoxic hepatic injury sufficient to cause hepatic necrosis. This, together with severe intestinal symptoms suggestive of bowel infarction, was the principal clinical manifestation in the following patient.

\section{Case report}

A 24 year old woman had complained of a throbbing headache for three months before admission whenever she was in the kitchen. A gas water heater was subsequently shown to have a blocked flue. On the night of admission she had been working in the kitchen for one and a half hours when she developed a headache and felt faint. She could remember continuing to work there for a time but then became unconscious and was found two hours later. The total exposure time to carbon monoxide was three and a half hours.

When admitted to the local hospital 15 minutes later she was in deep coma, with a temperature of $33^{\circ} \mathrm{C}$ (rectal) and blood pressure $90 / 60 \mathrm{~mm} \mathrm{Hg}$. There was no jaundice, hepatomegaly, or focal neurological sings. Her skin was pink and the diagnosis of carbon monoxide poisoning was confirmed by a carboxyhaemoglobin saturation of $34 \%$ in the blood. Results of other investigations 12 hours after exposure were: haemoglobin concentration $17.7 \mathrm{~g} / \mathrm{dl}$, leucocyte count $33 \times 10^{9} / 1$, platelet count $101 \times 10^{9} / 1$, concentration of fibrin degradation products raised, prothrombin time 47 seconds (control 12 seconds), and blood urea concentration $9.1 \mathrm{mmol} / 1(56 \mathrm{mg} / 100 \mathrm{ml})$. No drugs were found in the serum and there was no history of excess alcohol ingestion. She was treated with $100 \%$ oxygen and fresh frozen plasma because of the prolonged prothrombin time. Twelve hours later she regained consciousness but then started to complain of abdominal pain, which was accompanied by loose stools containing blood. Forty eight hours after admission the pain had worsened and bowel infarction was suspected. At laparotomy the bowel was seen to be blue but viable. She failed to regain consciousness and it was found that the serum aspartate transaminase activity had been $1137 \mathrm{IU} / \mathrm{l}$ and the prothrombin time 55 seconds in a sample taken six hours before operation.

Next day, some 64 hours after admission, she was transferred to King's College Hospital, where she was found to be jaundiced with signs of grade 3 hepatic encephalopathy. Investigations showed that hepatic and renal function had deteriorated further-serum bilirubin concentration $60 \mu \mathrm{mol} / 1$ $(3.5 \mathrm{mg} / 100 \mathrm{ml})$, aspartate transaminase activity $5000 \mathrm{IU} / 1$, prothrombin time 45 seconds, urea concentration $18.0 \mathrm{mmol} / 1(108 \mathrm{mg} / 100 \mathrm{ml})$, creatinine concentration $510 \mu \mathrm{mol} / 1(5.8 \mathrm{mg} / 100 \mathrm{ml})$. Tests for hepatitis B surface antigen, $\operatorname{IgM}$ anti-HBc, and $\operatorname{IgM}$ antihepatitis $A$ virus gave negative results. A renogram made with diethylenetriamine penta-acetic acid showed changes of acute tubular necrosis and she required haemodialysis for five days. By the seventh day after the incident her conscious level had returned to normal and the diarrhoea and abdominal tenderness had resolved. By the 11 th day the serum aspartate transaminase activity and prothrombin time were normal. A biopsy specimen of liver obtained on the 15th day showed evidence of confluent cell loss with collapse of reticulum and accumulation of pigment macrophages. There was evidence of regeneration with prominent microvesicular fatty infiltration of the surviving parenchyma.

\section{Comment}

Usually a carboxyhaemoglobin concentration of $60 \%$ or higher is needed for coma to develop, and at a saturation of $34 \%$, as in this patient, only confusion is present. ${ }^{2}$ Once the patient is breathing uncontaminated air, however, the dissociation of carboxyhaemoglobin is initially rapid. ${ }^{2}$ The carboxyhaemoglobin concentration in this patient was measured one hour after she had been removed from the contaminated room. Hence the peak concentration of carboxyhaemoglobin was probably higher and more than enough to account for her initial coma. Liver and bowel are sensitive to hypoxia. ${ }^{4}$ In this case the hypoxia resulting from the carbon monoxide was sufficient to initiate the events that finally resulted in severe hepatic and bowel damage.

Surgery and anaesthesia reduce hepatic perfusion ${ }^{4}$ and exacerbate diffuse parenchymal liver disease. This has been well documented after infectious hepatitis and in patients with cirrhosis who are operated on. ${ }^{5}$ Without these added insults the hepatic necrosis may well have remained clinically latent in this patient, even though before laparotomy there was already evidence of severe hepatic necrosis (prothrombin time 55 seconds, serum transaminase activity $1137 \mathrm{IU} / \mathrm{l})$. After laparotomy the clinical picture was of fulminant hepatic failure, although recovery was rapid. Hepatic damage has not been reported in carbon monoxide poisoning, but clinically latent forms may be more common than has been recognised hitherto and the possibility needs to be borne in mind during the management of these patients.

We thank Dr P B Portmann for the histological report on the liver biopsy specimen.

1 Jackson $\mathrm{DL}$, Menzes $\mathrm{MD}$. Accidental carbon monoxide poisoning. $7 A M A$ 1980;243:772-4. 2 Winter PM, Miller JN. Carbon monoxide poisoning. FAMA 1976;236:1502-4. gastroenteritis. BrMed ${ }^{\prime} 1980 ; 281: 214-5$.

4 Powell-Jackson PR, Greenway $B$, Williams $R$. Adverse effects of exploratory laparotomy in patients with unsuspected liver disease. $B r \mathcal{H}$ Surg 1982;69:449-53.

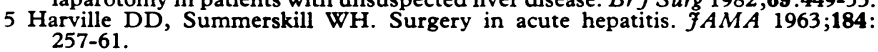

(Accepted 8 August 1984)

Liver Unit, King's College Hospital and School of Medicine and Dentistry, London SE5

ALASTAIR WATSON, MA, MRCP, medical registrar

ROGER WILLIAMS, MD, FRCP, director of liver unit

Correspondence to: Dr Roger Williams.

\section{Failure to thrive owing to inappropriate diet free of gluten and cows' milk}

The hazards of nutritionally inadequate exclusion diets for infants have been outlined. ${ }^{1}$ We describe an infant given such a diet on professional advice, whose consequent failure to thrive necessitated admission to hospital.

\section{Case report}

A $7 \frac{1}{2}$ month old boy presented with pallor and weight loss. He had been born at 39 weeks' gestation after a normal pregnancy and delivery, weighing $4100 \mathrm{~g}$ (above the 90th centile). He had been breast fed until 4 months old, when cows' milk and solids were added. His mother had sought advice because of his persistent crying during and after feeds, which was associated with some regurgitation but no diarrhoea. He also had facial eczema. She had been advised by her health visitor to replace cows' milk with a formula based on soybean and to withdraw food containing gluten. During the next six weeks he lost over $600 \mathrm{~g}$ in weight.

On examination he was thin and alert with wasting of the arms, legs, and buttocks. He had an eczematous rash on his left cheek and the napkin area. He weighed $6.3 \mathrm{~kg}$ (below the $3 \mathrm{rd}$ centile). His mucous membranes were pink. Investigations showed haemoglobin concentration $11.5 \mathrm{~g} / \mathrm{dl}$ with a normal film and red cell variables; white cell count $14.7 \times 10^{9} / 1(37 \%$ neutrophils, $57 \%$ lymphocytes, $3 \%$ monocytes, $3 \%$ eosinophils); erythrocyte sedimentation rate $10 \mathrm{~mm}$ in the first hour; plasma concentrations of sodium $138 \mathrm{mmol}(\mathrm{mEq}) / 1$, potassium $4.7 \mathrm{mmol}(\mathrm{mEq}) / 1$, bicarbonate $18 \mathrm{mmol}(\mathrm{mEq}) /$ 1, urea $7 \mathrm{mmol} / 1(42 \mathrm{mg} / 100 \mathrm{ml})$, creatinine $57 \mathrm{mmol} / 1(645 \mathrm{mg} / 100 \mathrm{ml})$, total protein $71 \mathrm{~g} / 1$, and albumin $49 \mathrm{~g} / 1$; and normal serum concentrations of IgG, IgA, and IgM. His urine was sterile, and no pathogens, ova, or cysts were isolated from his stools.

He was given a normal diet supplemented by breast feeding. Dietary assessment showed that his previous diet had been adequate in protein, iron, calcium, and vitamin $C$ but had yielded a daily energy intake of only $0.4 \mathrm{MJ}(97 \mathrm{kcal}) / \mathrm{kg}$ calculated on actual weight (equivalent to $0.3 \mathrm{MJ}$ (72 kcal)/kg calculated on a weight corresponding to the 50 th centile) owing to an inadequate intake of breast milk and soybean formula (maximum 227 $\mathrm{ml}$ daily). In addition, his solids had been restricted because his mother was unsure which foods contained gluten. In hospital his diet yielded a daily energy intake of $0.58 \mathrm{MJ}(137 \mathrm{kcal}) / \mathrm{kg}$ calculated on actual weight $(0.45 \mathrm{MJ}$ $(106 \mathrm{kcal}) / \mathrm{kg}$ for a weight corresponding to the $50 \mathrm{th}$ centile). He gained $600 \mathrm{~g}$ in weight in 12 days and was discharged. At 11 months old he had regained a position on the 50th centile for weight $(10.0 \mathrm{~kg})$.

\section{Comment}

This infant's dramatic increase in weight with a normal diet indicated that the inadequate intake of energy that he derived from 
the diet free of gluten and cows' milk was the cause of his failure to thrive. The lack of new gastrointestinal symptoms and the normal results of investigations made allergy to the soybean protein an unlikely explanation for his weight loss.

The incidence of coeliac disease proved by jejunal biopsy in patients with eczema is less than $1 \%{ }^{2}$ There is no justification for withdrawing gluten unless malabsorption is present and coeliac disease is suspected, when prior jejunal biopsy is mandatory. Ingestion of cows' milk and infantile eczema are associated, ${ }^{3}$ and the many symptoms attributable to intolerance of cows' milk have received medical and public attention. ${ }^{45}$ The criteria for diagnosing intolerance to cows' milk are strict, ${ }^{4}$ and referral to hospital is reasonable when symptoms are persistent or severe, and essential if coeliac disease is suspected. Empirical changes in diet are sometimes necessary but should never be undertaken without careful review of weight gain. Complex alterations in diet should be undertaken only with the advice of a dietitian.

We thank Dr M Moncrieff for permission to report this case. WOT-M is supported by an Action Research training fellowship. 1 Tripp JH, Francis DEM, Knight JA, Harries JT. Infant feeding practices : a cause

2 Shuster S, Marks J. Systemic effects of skin disease. London: Heinemann Medical,

3 Atherton DJ, Sewell M, Soothill JF, Wells RS. A double-blind controlled crossover trial of an antigen avoidance diet in atopic eczema. Lancet $1978 ; 1: 401-3$. 4 Anderson CM, Burke V. Other disorders of the small intestine associated with malabsorption. In: Anderson CM, Burke V, eds. Paediatric gastroenterology. Oxford: Blackwell, 1975:229.

5 Carter J. Is your child allergic to milk ? Mother July 1983:53.

(Accepted 8 August 1984)

Paediatric Department, John Radcliffe Hospital, Oxford OX3 9DU WILLIAM O TARNOW-MORDI, MRCP, DCH, research fellow CATHERINE MOSS, BA, medical student

KAREN ROSS, SRD, paediatric dietitian

Correspondence to: Dr W O Tarnow-Mordi.

\section{Spontaneous choledochal-colonic fistula treated by duodenoscopic sphincterotomy}

Enterobiliary fistulas are a well recognised complication of cholelithiasis. ${ }^{12}$ The most common are cholecystoduodenal with cholecystocolonic being the second most common. Initially the complication was thought to be rare, but with the advent of endoscopic retrograde cholangiography the rate of recognition has increased.

We report a patient with a choledochal-colonic fistula secondary to cholelithiasis, diagnosed by barium enema and treated by duodenoscopic sphincterotomy.

\section{Case report}

An 87 year old woman presented with a six day history of central upper abdominal discomfort associated with nausea but no vomiting. She was of previous good health, except for mild congestive cardiac failure treated by a combined frusemide-potassium preparation (Lasikal, two tablets daily). Initial examination elicited epigastric tenderness but no rebound tenderness or guarding. There was no other physical abnormality. Biochemical investigation showed mild renal failure (plasma urea concentration $15.4 \mathrm{mmol} / \mathrm{l}$ $(93 \mathrm{mg} / 100 \mathrm{ml})$, creatinine concentration $178 \mu \mathrm{mol} / 1(2.0 \mathrm{mg} / 100 \mathrm{ml}))$, mild hypokalaemia (potassium concentration $3.0 \mathrm{mmol}(\mathrm{mEq}) / \mathrm{l}$ ), but normal sodium and chloride values. Plain abdominal radiographs were normal. Her diuretic was stopped.

The abdominal pain remained unchanged but she began to have watery diarrhoea with up to 10 bowel actions a day. The hypokalaemia worsened, with readings of $\mathbf{2} \cdot 4-2 \cdot 8 \mathrm{mmol} / 1$. Repeated measurements of liver function values were normal. Sigmoidoscopy to $20 \mathrm{~cm}$ showed normal appearances. Barium enema disclosed a choledochal-colonic fistula with two gall stones within the common bile duct (figure). An endoscopic cholangiogram confirmed these findings and at sphincterotomy $(1.5 \mathrm{~cm})$ one of the stones was removed. The second stone was not removed but the sphincterotomy was large enough to allow free drainage of bile and subsequent passage of the stone.

Over the next three days there was resolution of the diarrhoea and return to normal bowel action. The plasma potassium value rose to normal within
48 hours and was maintained without oral supplements. At outpatien review four and 12 weeks after the sphincterotomy she had remained well and was without symptoms.

\section{Comment}

Anatomical enterobiliary fistulas are not rare, being documented in $0.4 \%$ of cases at necropsy and in $13.6 \%$ of patients in one series examined by endoscopic retrograde cholangiography. ${ }^{3}$ Those requiring treatment, however, are uncommon; Glenn et al recorded

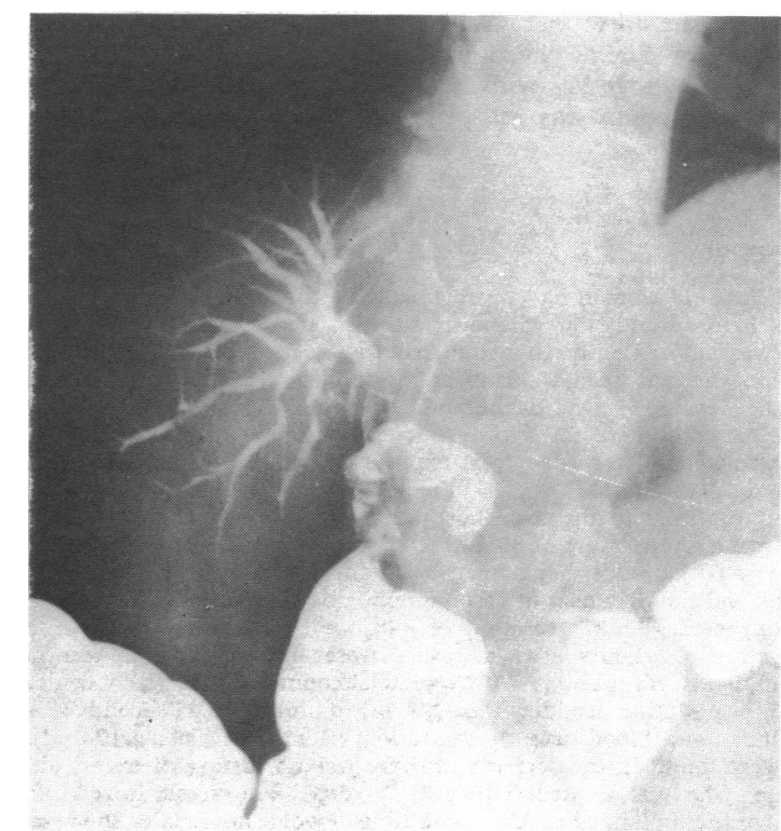

Spot film taken from barium enema examination showing choledochal-colonic fistula.

only 105 cases over 46 years at the Cornell Medical Center, New York. ${ }^{1}$ Most are seen in elderly people secondary to cholelithiasis but other causes are trauma, operative surgery, neoplasms, and peptic ulceration. Symptoms are non-specific but may be cholangitis, persistent diarrhoea, electrolyte imbalance, malabsorption, gall stone ileus, or very rarely major bleeding. ${ }^{4}$ Treatment in patients with symptoms has traditionally been open abdominal surgery with excision of the fistula or a drainage procedure, but this carries an operative mortality of $6 \%$ and morbidity of $15 \%{ }^{1}$

The removal of common bile duct stones by endoscopic methods is established practice with a morbidity of about $10 \%$ and mortality below $1 \%$. Endoscopic treatment of an internal biliary fistula has not been reported, though the same technique has been successfully used to treat an external fistula. ${ }^{5}$ We did not document the healing of the fistula in our patient but the resolution of her symptoms and rapid correction of the hypokalaemia made this likely. We suggest that endoscopic sphincterotomy should be considered in cases of symptomatic biliary fistulas, especially when major surgery is undesirable.

1 Glenn F, Reed C, Grafe WR. Biliary enteric fistula. Surg Gynecol Obstet 1981; 153:527-31.

2 Slasky SB, Campbell WL. Cholecystosigmoid fistula. Am f Gastroenterol 1983; 78:276-9.

3 Ghazi A. Enterobiliary fistula and ERCP. Am f Gastroenterol 1977;68:81-3.

4 Kaplan BJ. Massive lower gastrointestinal hemorrhage from cholecystocolic fistula. Dis Colon Rectum 1967;10:191-7.

5 O'Rahilly S, Duignan JP, Lennon JR, O'Malley E. Successful treatment of a postoperative external biliary fistula by endoscopic papillotomy. Endoscopy 1983;15:68-9.

(Accepted 8 August 1984)

Department of Medicine, Seacroft Hospital, Leeds 14

$P$ BANNISTER, MB, MRCP, tutor in medicine

C BENNETT, $M B$, CHB, senior house officer

M E DENYER, MB, MRCP, consultant physician

Correspondence to: Dr P Bannister, Department of Medicine, St James's University Hospital, Leeds. 